\title{
Experts split on adequacy of surveillance since SARS
}

A decade ago, after the SARS epidemic killed 44 people, the ensuing federal expert panel called for a national public health agency to dramatically expand emerging infectious disease surveillance.

Has that been achieved?

Yes, says Dr. Frank Plummer, who served on the panel as the scientific director general of the National Microbiology Laboratory.

Today, Plummer is the chief science officer for the Public Health Agency of Canada (PHAC), the agency that the panel's report, Learning From SARS: Renewal of Public Health in Canada, urged into existence. He says surveillance has improved vastly. "Our alerting systems are extremely robust."

As evidence, Plummer points to three disease-related national surveillance networks created or bolstered by PHAC and its provincial and territorial counterparts since 2003.

The Canadian Network for Public Health Intelligence (CNPHI) gathers and relays disease surveillance information to and from 3000 users - many of whom are clinicians in daily contact with the public - in 70 centres.

The Canadian Nosocomial Infection Surveillance Program (CNISP) tracks infectious disease events in 54 hospitals in ten provinces.

And the Canadian Integrated Program for Antimicrobial Resistance Surveillance (CIPARS), tracks antibiotic resistance both in food animals and retail meat in 59 abattoirs and numerous food retailers in British Columbia, the Maritimes, Ontario, Quebec and Saskatchewan.

According to Plummer, CNISP and CIPARS are yielding ever-growing insights into the dynamics and risks of numerous infectious organisms, while CNPHI allows the national public health community to share real-time information about clinical developments such as the emergence of SARS.

"It's the best system of its kind in the world" for alerting clinicians to new pathogens and emerging epidemics, Plummer says.

Dr. Vivek Goel, president and CEO of Public Health Ontario, an arm's-

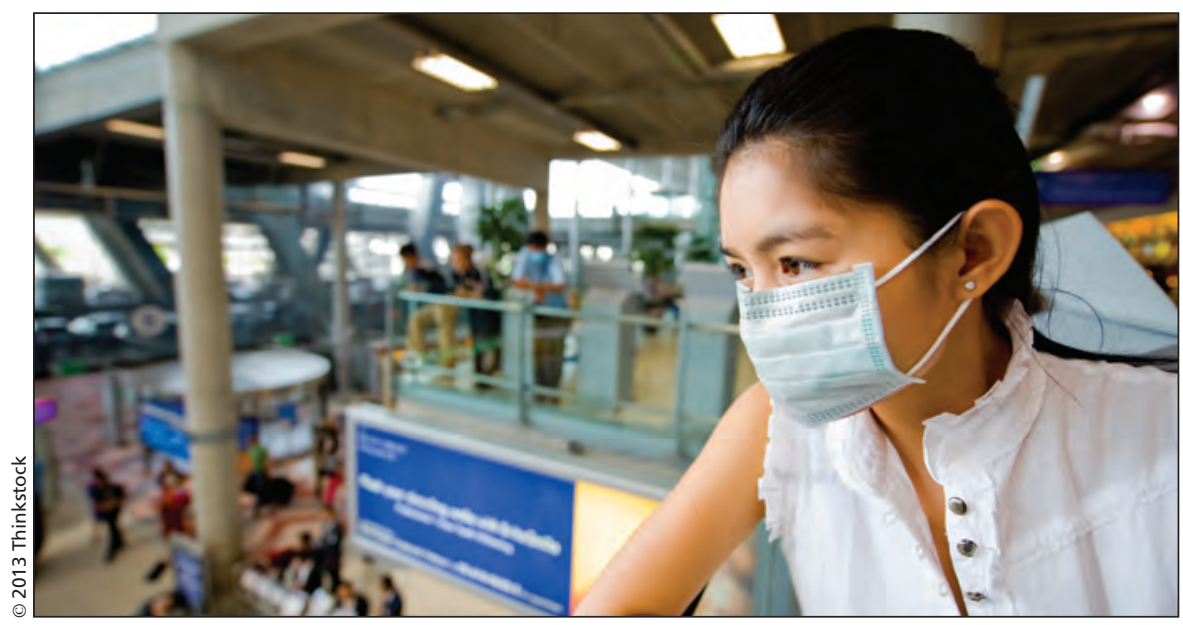

The SARS outbreak a decade ago prompted work on Canada's surveillance systems.

length agency that coordinates disease surveillance and control, agrees that remarkable improvements have been made. During the 2009 H1N1 epidemic "we had much more rapid sharing of information across the country.'

But not everyone is as upbeat as Goel and Plummer about PHAC's efforts in national disease surveillance. Dr. Andrew Simor, a member of CNISP's Hospital Epidemiology Committee, says CNPHI is not a national surveillance system but merely "a means of inputting surveillance data electronically." The data is not widely available, he explains, due to restrictions on access.

Dr. Danuta Skowronski, the epidemiology lead for influenza and emerging respiratory pathogens at the British Columbia Centre for Disease Control, agrees. CNPHI, she explains, is far too limited in scope to be called a robust national network like those in the US and Europe. "You need to have a means of directly communicating with and hearing from very large numbers clinicians," she says.

Simor and Skowronski and others also express reservations about PHAC's efforts to extend hospital-based surveillance through the CNISP network.

Although the network is welldesigned, says Dr. John Conly, a CNISP Hospital Epidemiology Committee member, it is underfunded and does not reach beyond major cities. There are also long delays in releasing data surveys and reports from CNISP and CIPARS. "Would Canada be better prepared now for SARS or the novel coronavirus?" Conly asks. "I am not sure."

Dr. Johann Pitout, an infectious disease investigator with Calgary Laboratory Services says that at the very least Ottawa should insist on mandatory reporting of high-risk classes of drug-resistant infections.

In Toronto, Ontario, Dr. Don Low, microbiologist-in-chief at the University Health Network, agrees much more must be done to coordinate national surveillance. But he notes that the response to the $2009 \mathrm{H} 1 \mathrm{~N} 1$ outbreak indicated solid progress has been made since SARS, and he singles out PHAC's National Microbiology Lab for special praise.

In Kingston, Ontario, Dr. Richard Zoutman, a member of Ontario's Infectious Disease Advisory Committee, also says he sees solid progress on many fronts, including the containment of some multidrug-resistant pathogens, such as Methicillin-resistant Staphylococcus aureus (MRSA). And although he believes Canada would be better positioned now to respond to SARS, there remains insufficient surveillance data from both hospitals and community sources. "We have a long way to go," he adds, "We're not doing enough." Paul Christopher Webster, Toronto, Ont.

CMAJ 2013. DOI:10.1503/cmaj.109-4449 